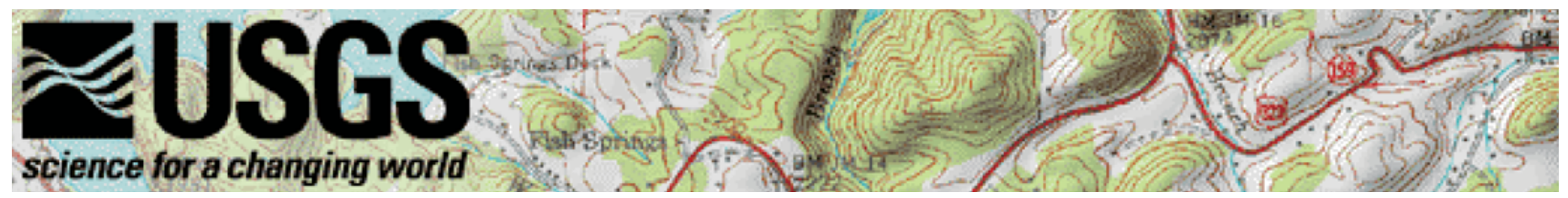

\title{
The National Map - Pennsylvania Pilot Project
}

\section{The Nation Needs The National Map}

Governments depend on a common set of geographic base information as a tool for economic and community development, land and natural resource management, and health and safety services. Emergency management and defense operations rely on this information. Private industry, nongovernmental organizations, and individual citizens use the same geographic data. Geographic information underpins an increasingly large part of the Nation's economy.

Available geographic data often have the following problems:

They do not align with each other because layers are frequently created or revised separately,

They do not match across administrative boundaries because each producing organization uses different methods and standards, and

They are not up to date because of the complexity and cost of revision.

The U.S. Geological Survey (USGS) is developing The National Map to be a seamless, continuously maintained, and nationally consistent set of online, public domain, geographic base information to address these issues. The National Map will serve as a foundation for integrating, sharing, and using other data easily and consistently.

In collaboration with other government agencies, the private sector, academia, and volunteer groups, the USGS will coordinate, integrate, and, where needed, produce and maintain base geographic data.

The National Map will include digital orthorectified imagery; elevation data; vector data for hydrography, transportation, boundary, and structure features; geographic names; and land cover information. The data will be the source of revised paper topographic maps.

Many technical and institutional issues must be resolved as The National Map is implemented. To begin the refinement of this new paradigm, pilot projects are being designed to identify and investigate these issues. The pilots are the foundation upon which future partnerships for data sharing and maintenance will be built.

\section{The Pennsylvania Pilot Project}

The Pennsylvania Department of Conservation and Natural Resources, Bureau of Topographic and Geologic Survey, is coordinating orthoimagery collection and data standards, at the county level, for the 67 counties of the Commonwealth. This pilot project will provide local, high-resolution source data for image requirements and cartographically derived theme data to meet the goals of The National Map. The planned maintenance cycle for these data will greatly improve the currentness for spatial data in Pennsylvania. This project will reduce duplication of effort and form a statewide standard for orthoimagery. The Pennsylvania pilot project area will consist of the Susquehanna Economic Development Area Council Of Governments (SEDACOG), a group of counties in central Pennsylvania. The counties have the largest contiguous and most complete collection of geospatial data in the State and are willing to participate in the pilot project. The SEDACOG is within the Chesapeake Bay watershed, and this pilot project will improve the data inventory knowledge and data access for the Chesapeake Bay's program of scientific studies, policy development, and monitoring activities.

A second pilot region is the Southwestern Pennsylvania Commission (SPC), a nine-county region in the southwest part of the State, including the Pittsburgh metropolitan area.

The SPC has taken 1:2,400-scale aerial photographs, which have been scanned and rectified to yield 1-foot resolution orthoimagery. This orthoimagery will provide an enhanced source for base cartographic vector data that will integrate with local boundary and transportation data and contribute to The National Map.

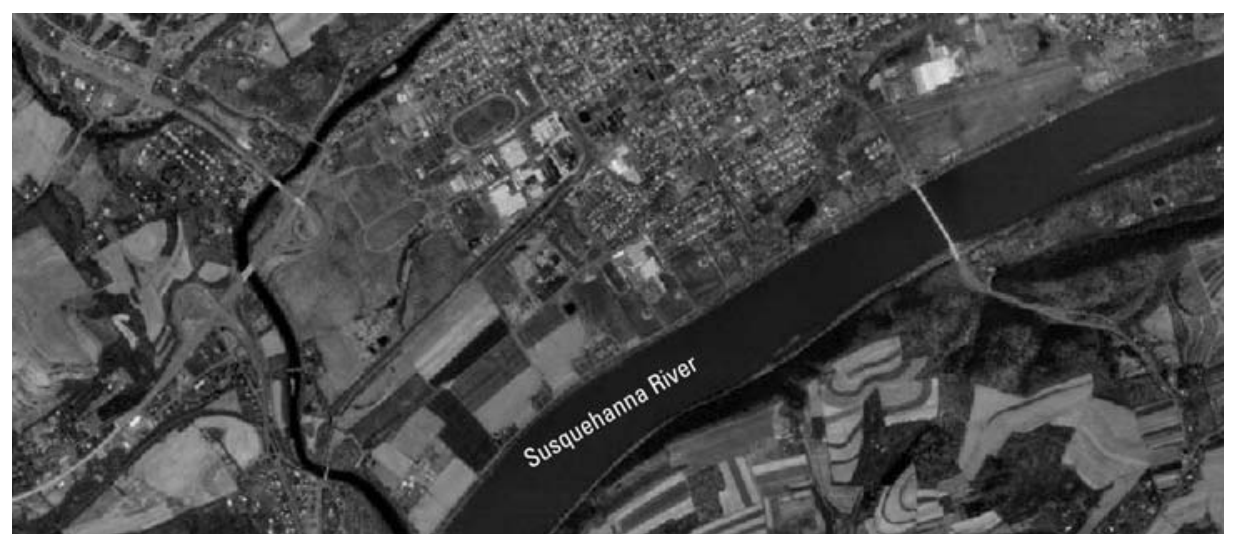

SEDACOG region, Bloomsburg, PA 
In Lancaster County, which holds similar orthoimagery data, USGS National Hydrographic Dataset information will be revised, and large-scale land cover will be integrated with local parcel and zoning data to provide a true land use/land cover dataset for watershed management and modeling. This application will help devise management strategies for sediment reduction in the Susquehanna River, which accounts for approximately 50 percent of the surface water flowing into the Chesapeake Bay. The updated hydrographic data also will meet goals of The National Map for current, consistent, and accurate base geographic data.

For the data distribution phase of the Pennsylvania pilot project, the USGS EROS Data Center will serve Web-based orthoimagery and vector data available from the State. In addition, links will be established to selected local and Federal data to provide downloadable highresolution Geographic Information System data. At a future time, the dataserving function may be moved and managed from an Eastern Region USGS facility. The Commonwealth of Pennsylvania will also develop a "mirror" site, so that data will be available from multiple sources, should one site be disabled.

Longer range plans call for other State, Federal, and regional data to be tied to the orthoimagery base to provide complete content as envisioned by The National Map, with links to other geographically referenced datasets. Example data include Bureau of the Census TIGER data, E911 emergency

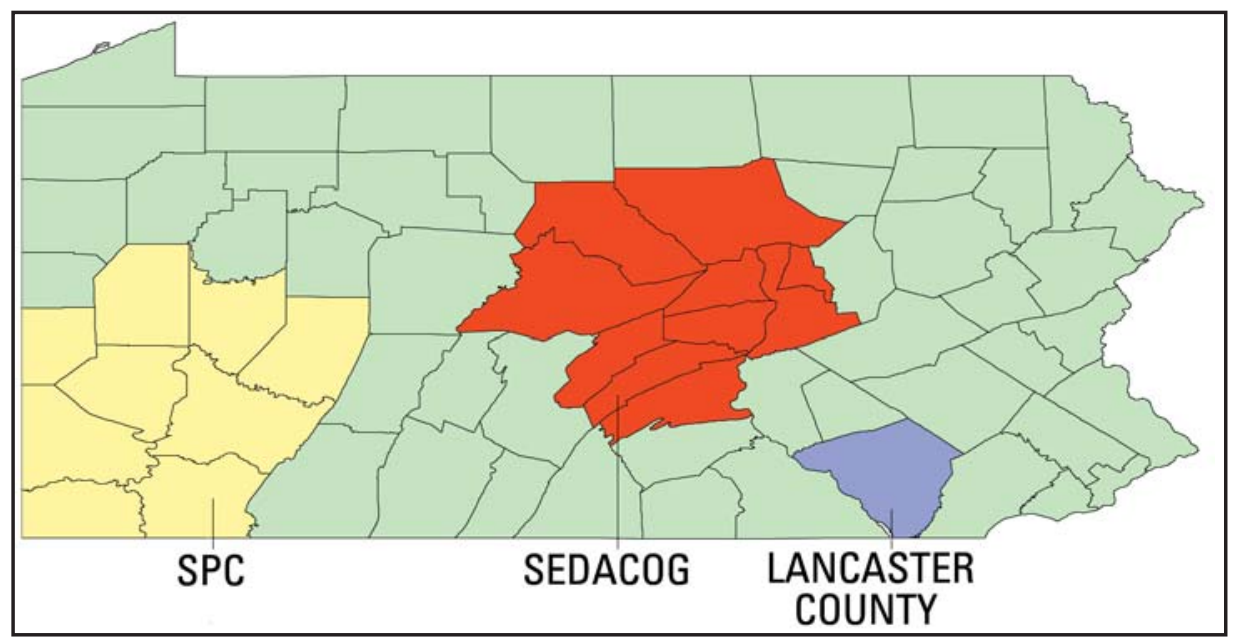

The National Map Pilot Areas in Pennsylvania

response data, and Light Detection and Ranging high-resolution elevation data. These data will support the Federal Emergency Management Agency's flood plain mapping requirements, as well as the study of subsidence issues related to coal mining and karst topography.

\section{More Information About The Pennsylvania Pilot Project}

Dr. Jay Parrish

Pennsylvania Dept. of Conservation and Natural Resources

Bureau of Topographic and Geological Survey

Evangelical Press Building, 2nd Floor

1500 North 3rd St..

Harrisburg, PA 17105-8453

Phone: 717-787-2169

E-mail: jayparrish@state.pa.us

Or
Roger Barlow

U.S. Geological Survey

National Mapping Program Liaison

MS 559 National Center

Reston, VA 20192

Phone: 703-648-5189

E-mail: rbarlow@usgs.gov

\section{More Information About The National Map}

We welcome your comments on The National Map mission and strategies. You can view and download the full report at nationalmap.usgs.gov. Please share your thoughts about the vision with the USGS by e-mail at nationalmap@usgs.gov or by mail to USGS-National Map, MS 511 National Center, 12201 Sunrise Valley Drive, Reston, VA 20192. 